This document is the Accepted Manuscript version of a Published Work that appeared in final form in British Journal of Healthcare Management, copyright (C) MA Healthcare, after peer review and technical editing by the publisher. To access the final edited and published work see https://doi.org/10.12968/bjhc.2017.23.5.198

\title{
Election 2017: The future
}

\section{Dr Bryan McIntosh, Associate Dean - International, Reader in Organisational Management and Leadership, University of Bradford}

On the $8^{\text {th }}$ of June 2017 the United Kingdom will go the polls. The NHS will be central to the campaign. This will not just be a campaign concerned about NHS funding it never really is, there are always so many other issues. However, it will be either be consciously or subconsciously about the nature of the NHS in the immediate foreseeable future.

The central issues are clear, new treatments for a growing and aging population mean that pressures on the service are greater than they have ever been. Rising Waiting times and strained operational delivery constrained by the need to financially balance budgets. Perhaps the Conservative manifesto promise of 2015, to provide urgent and emergency care 24 hours a day, 7 days a week may fall by the wayside. This fall of this commitment may be no bad thing, urgent care services are struggling to cope with rising demand up to 3 million A\&E visits could have been better dealt with elsewhere. There are difficulties in admitting sicker patients into hospital beds and discharging them promptly back home. An election manifesto pledge may well be met with approval in some quarters of the NHS.

However, whatever party wins the election, the new Government over the next two years the NHS will need to take practical action to take the strain off A\&E. It will need to work closely with community services and councils. Hospitals need to be able to free up 2,000-3,000 hospital beds. As most NHS care is provided by general practice. The incoming Government will need to have enough GPs, backed up by the resources, support and other professionals required to enable them to deliver the quality of care they want to provide. While the United Kingdom Government claims that it has begun to reverse the historic decline in funding for primary care, and it has plans over the next two years to deliver $3,250 \mathrm{GP}$ recruits, with an extra 1,300 clinical pharmacists and 1,500 more mental health therapists but is that enough?

All parties have recognised the challenges faced by mental health services in the short-term. The NHS needs a substantial increase in investment to enable more people to services. With an aging population the NHS needs to adapt to their needs, helping frail and older people stay healthy and independent, avoiding hospital stays where possible, improving prevention and care for patients, as well as ensuring financial sustainability. All parties in some shape or form advocate better integration of GP, community health, mental health and hospital services, as well as more joined up working with home care and care homes. However, can they deliver this within the narrative of a service in crisis?

Whoever is office they will need to accelerate this way of working to more of the country, through partnerships of care providers and commissioners in an area (Sustainability and Transformation Partnerships). Within England some areas are now ready to go further and more fully integrate their services and funding, and provide accountable care systems. Working together with patients and the public, NHS commissioners and providers, as well as local authorities and other providers of health and care services to provide care, while taking on new responsibilities for improving the health and wellbeing of the population they cover but will this be maintained and it is enough?

Nothing is possible without the NHS staff. Although the NHS has 3,000 more doctors and 5,000 more nurses than 2014, and productivity continues to improve, frontline staff face great personal and organisational pressures from rising demand but with Brexit how will the future Government staff the NHS frontline? While the NHS arguably is one of the leanest publicly-funded health services in 
the industrialised world, the Conservative Government present an argument that there are still opportunities to do better, as set out in the NHS' 10 Point Efficiency Plan but is this the case?

All of this is the immediate short-term, the main medium to long-term question remains how is the NHS funded. The stark reality is as long as a Government is committed to eliminating the deficit the NHS will be financially challenged. Services will decline unless the Government of the day considers that the political price is too high. However, combining a free at the point of use NHS with a heavily means-tested social care is extremely difficult. There are a number of other ways of providing universal cover, including the social insurance model used in Germany, the Netherlands and Switzerland. If an "austerity" party gains power it is increasingly inevitable that either charges or that a European-style social insurance system will be introduced in some shape or form. If it is the latter, this will have a profound impact on the NHS, its entire structure and workforce. It will be transformed from a command and control organisation to an organisation fully located in the market place with all the strengths and weaknesses that the market brings. It would be a profound change and mean the end of the structure of the NHS as we have knownfrom its conception.

The next Government whoever it is, will be faced with immense challenges, there are considerable risks to delivery of a stretched agenda and all parties will be faced by limited resources. If they can address the immediate central issues and provide measures which address them they can potentially deliver a better, more joined-up and more responsive NHS. One that collaborates to ensure that services are designed around patients and that is built on a more sustainable financial footing, so that it can continue to deliver health and high quality care - now and for future generation. However, if they fail to provide solutions and a centre right Government is in power, the NHS will become increasing vulnerable to an ideological driven agenda, one which would means its utter transformation. This would be to such extent that makes its survival as we know it, an uncertainty. 